\title{
Breast lesions excised via vacuum-assisted system: could we get any clues for B3 lesions before excision biopsy?
}

Liang Zheng ${ }^{1,2 \dagger}$, Fufu Zheng ${ }^{3 \dagger}$, Zhaomin Xing ${ }^{1,2 \dagger}$, Yunjian Zhang ${ }^{2 \dagger}$, Yongxin $\mathrm{Li}^{4}$, Hongbiao Xu ${ }^{2}$, Yuanhui Lai ${ }^{2^{*}}$, Jie $\mathrm{Li}^{\mathrm{i}^{*}}$ and Wenjian Wang ${ }^{1,2^{*}}$

\begin{abstract}
Background: The purpose of this study was to determine the validity of the ultrasound features as well as patient characteristics assigned to B3 (uncertain malignant potential) breast lesions before vacuum-assisted excision biopsy (VAEB).

Methods: This study population consisted of 2245 women with breast-nodular abnormalities, which were conducted ultrasound-guided VAEB (US-VAEB). Patient's clinical and anamnestic data and lesion-related ultrasonic feature variables of B3 captured before US-VAEB were compared with those of benign or malignant cases, using histopathological results as a benchmark.

Results: The proportions of benign, B3 and malignant breast lesions diagnosed post-US-VAEB were 88.5, 8.2 and $3.4 \%$ respectively. B3 high frequent occurred in BI-RADS-US grade $3(7.7 \%)$, grade $4 a(11.0 \%)$ and grade $4 \mathrm{~b}(9.1 \%)$. The overall malignancy underestimation rate of B3 was 4.4\% (8/183). Malignant lesions were found mostly in the range of BI-RADS grade $4 \mathrm{~b}(27.3 \%)$, grade $4 \mathrm{c}(33.3 \%)$ and grade 5 (100\%). Multivariate binary logistic regression analyses (B3 vs benign) showed that non-menopausal patients (95\% Cl 1.628-8.616, $P=0.002)$, single $(95 \% \mathrm{Cl} 1.370-$ $2.650, P=0.000)$ or vascularity $(95 \% \mathrm{Cl} 1.745-4.150, P=0.000)$ nodules in ultrasonic features were significant risk factors for B3 occurrences. In addition, patients elder than 50 years ( $95 \% \mathrm{Cl} 3.178-19.816, P=0.000)$, unclear margin ( $95 \% \mathrm{Cl} 3.571-14.119, P=0.000$ ) or suspicious calcification ( $95 \% \mathrm{Cl} 4.010-30.733, P=0.000$ ) lesions were significantly associated with higher risks of malignant potentials for B3 cases (malignant vs B3).

Conclusion: The results of this study indicate that ultrasound findings and patients' characteristics might provide valuable information for distinguishing B3 lesions from benign breast abnormalities before VAEB, and help to reduce malignancy underestimation of $\mathrm{B} 3$.
\end{abstract}

Keywords: B3 breast lesion, Uncertain malignant potential, Vacuum-assisted excision biopsy, Breast ultrasonography, Malignancy underestimation

\footnotetext{
*Correspondence: wangwj28@mail.sysu.edu.cn; lijie78@mail.sysu.edu.cn; lai_yuanhui@126.com

'Liang Zheng, Fufu Zheng, Zhaomin Xing and Yunjian Zhang contributed equally to this work.

${ }^{2}$ Department of Thyroid and Breast Surgery, the First Affiliated Hospital of Sun Yat-sen University, Guangzhou 510080, Guangdong, China

'Laboratory of Department of Surgery, the First Affiliated Hospital of Sun

Yat-sen University, Guangzhou 510080, Guangdong, China

Full list of author information is available at the end of the article
}

(C) The Author(s). 2021 Open Access This article is licensed under a Creative Commons Attribution 4.0 International License, which permits use, sharing, adaptation, distribution and reproduction in any medium or format, as long as you give appropriate credit to the original author(s) and the source, provide a link to the Creative Commons licence, and indicate if changes were made. The images or other third party material in this article are included in the article's Creative Commons. licence, unless indicated otherwise in a credit line to the material. If material is not included in the article's Creative Commons licence and your intended use is not permitted by statutory regulation or exceeds the permitted use, you will need to obtain permission directly from the copyright holder. To view a copy of this licence, visit http://creativecommons.org/licenses/by/4.0/ The Creative Commons Public Domain Dedication waiver (http://creativecommons.org/publicdomain/zero/1.0/) applies to the data made available in this article, unless otherwise stated in a credit line to the data. 


\section{Highlights}

- For the first time, we found that breast lesions distributed in BI-RADS-US grade 3-4b presenting with one or more factors of non-menopausal patients, single or vascularity nodules were significantly associated with risks of B3 occurrences.

- B3 cases diagnosed post-US-VAEB, which were classified in the range of BI-RADS-US grade $4 \mathrm{~b}-5$ before VAEB, with one or more factors of patients elder than 50 years, unclear margin or suspicious calcification lesions, were remarkably related to risks of malignant potentials.

\section{Background}

Over the last decades, incidence rates of breast cancers in women have been significantly rising. Moreover, breast cancer is the most frequently diagnosed cancer and is also the leading cause of death from cancer in the world as well as in China [1, 2]. For the reasons, breast changes are the principal cause of anxiety in patients who consult physicians in outpatient [3]. In addition to history and physical examination, diagnostic imaging is often utilized by physicians to evaluate the malignant potentials of the breast abnormalities.

Since the initial release of the BI-RADS lexicon for ultrasound (BI-RADS-US) in 2003 [4], together with the rapid development of technique, ultrasound is getting more used for breast screening, especially in Asian women with dense breasts [5]. Compare to mammography, ultrasound examination is a portable, real-time, non-invasive, non-radiative, inexpensive, and highly reproducible method, and well accepted by patients [5-7]. BI-RADS-US is confirmed to be feasible to offer typical features for benign or malignant breast lesions $[8,9]$. Therefore, BI-RADS-US is often recognized as the qualified indication of biopsy or surgical excision for breast lesions [10]. Currently, US-VAEB tends to be regarded as the best diagnostic way to differentiate benign from malignant breast changes seen at imaging and is popular in China $[11,12]$. VAEB could replace core needle biopsy and open surgical biopsy for diagnoses of breast diseases and treatment of benign breast lesions [13, 14]. It has several advantages, including the ability to get more samples for a more reliable histological diagnosis, the ability to complete removal of the breast lesion, and performance under the real-time guidance of ultrasound [15]. The biopsy diagnoses can be usually categorized as normal/benign, B3 (uncertain malignant potential), or malignant [16, 17]. BI-RADS-US features of typical benign or malignant breast lesions are well concordance with the histological results of biopsies, which could help physicians/patients make choices easier before excision biopsy. However, B3 lesion is usually regarded as a post-
VAEB histological diagnosis because few studies are referring to imaging features specifically assigned to B3 before VAEB. Therefore, the diagnosis of B3 is much more challenging in clinical practice. It is reported that the approximate proportions of each biopsy results are normal/benign $70-98.89 \%$, B3 $<10 \%$, malignant $<2 \%$, respectively [18-20]. The data indicate that most breast changes need not excision biopsy. However, in clinical practice, to some extent, the trend of VAEB is to avoid malignancy underestimation of B3, which is subjective and depends on doctors' individual experience. With increasing concern about over-diagnosis and overtreatment through breast screening, it is regarded as a time to consider the possibility of B3 identification before VAEB.

This study aims to evaluate and compare the common features of ultrasound findings before US-VAEB as well as patient characteristics of B3 cases to those of normal or malignant cases based on histopathological results from US-VAEB.

\section{Methods \\ Study design and patient population}

The Institute Research Ethics Committee of the First Affiliated Hospital of Sun Yat-sen University granted permission for this retrospective study. Written informed consent was obtained from every patient for the use of the medical records for research purposes.

All methods were carried out in accordance with relevant guidelines and regulations.

A total of 2245 cases with breast nodules were performed US-VAEB in our institute, from June 2014 to December 2018. The inclusion criteria were as follows: (1) All patients included in the study group were women with a US-detectable breast lesion; (2) Availability of clinical and anamnestic data of patients, and ultrasound imaging reporting and data system lexicon for the breast lesions before US-VAEB; (3) The first time of US-VAEB; (4) Availability of histopathological report; (5) All cases were imaging followed up for at least 12 months after US-VAEB. No follow-up cases were excluded.

\section{Variables}

Clinical data for statistical analyses included patient ages at treatment (range 12-79 years), reproductive ages, menopause, the complaint of pain, palpable nodules, lesions in the left or right breast, and quadrant of lesions. Menopause usually was defined retrospectively as 12 months of amenorrhoea accompanying with or without menopausal symptoms [21]. Reproductive age comprised 15-49 years without abnormal menstruation [21]. Sonographic characteristics for the lesions were assessed referring to the American College of Radiology (ACR) Breast Imaging Reporting and Data System (BI-RADS) 
Atlas Fifth Edition [22], which included nodule multifocality, shape, orientation, margin, echo pattern, suspicious calcification, architectural distortion, duct changes, vascularity, skin changes, and lymph nodes. Posterior features were excluded because most cases missed the related information. In addition, orientation, architectural distortion and skin changes were rarely observed in the study cohort. And they did not meet the statistic analysis condition. Here, echo pattern comprised anechoic, hyperechoic, complex cystic and solid, hypoechoic or heterogeneous. Suspicious calcification comprised intra mass calcification and/or intra ductal calcification. Vascularity included internal vascularity and/or vessels in rim.

\section{Data analysis}

The SPSS 25.0 software package was used for all statistical calculations. Chi-square test / Fisher's exact test was utilized to compare the differences of ultrasonic features of B3 lesions and clinical and anamnestic data of the associated patients with those of benign or malignant cases. Univariate and multivariate binary logistic regression analyses were used to find independent predictive risk factors for B3 or malignant potentials. The result with $P$ value $<0.05$ was considered statistically significant.

\section{Results}

\section{Study population description}

Our database included 2245 women who had recentonset US-detectable breast findings. The mean age was 37.5 years (range 12-79 years). The most frequent complaint of patients was palpable nodules $(86.8 \%)$. The average diameter of the lesions was $13.2 \mathrm{~mm}$ (range 2$75 \mathrm{~mm}$ ). The less frequent complaints were pain (4.1\%) and nipple discharge (1.2\%), respectively. And $7.9 \%$ of cases are asymptomatic, which were image findings. All patients were addressed to undergo US-VAEB for the first time at our institute. $T$ he median duration of imaging follow-up post-US-VAEB was 24.7 months (range $12.0-60.0$ months).
The clinicopathologic characteristics of the cases are summarized in Table 1.

\section{BI-RADS-US category assessment based on histopathological results of VAEB}

Post-US-VAEB histopathological diagnoses confirmed that there were benign, B3, and malignant breast lesions as $1986(88.5 \%), 183(8.2 \%)$, and $76(3.4 \%)$, respectively. Malignant lesions account for the minimum amounts of VAEB cases, and the overwhelming majority of VAEB cases are nonmalignant disorders that are unnecessarily subjected to biopsy, which is consistent with previous reports $[23,24]$. Afterward, we subclassified the lesions according to their BI-RADS-US category assessment. The incidences of B3 and malignant breast lesions in each grade of BI-RADS-US were listed in Table 1. Notably, the prevalent range for $\mathrm{B} 3$ was in BI-RADS-US grade 3 $(7.7 \%)$, grade $4 \mathrm{a}(11.0 \%)$, and grade $4 \mathrm{~b}(9.1 \%)$. And they were rarely diagnosed in BI-RADS-US grade $4 \mathrm{c}$ or grade 5. On the other hand, the malignant lesions were mainly distributed in the range of BI-RADS-US grade $4 \mathrm{~b}$ $(27.3 \%)$, grade $4 \mathrm{c}(33.3 \%)$, and grade $5(100 \%)$, which are compatible with the literature [25].

\section{Malignancy underestimation rate and recurrence rate of B3}

Initially, there was a total of 183 cases of B3 lesions proved post-US-VAEB. The histopathological results of B3 subtypes were listed in Table 2. Meanwhile, one case of atypical ductal hyperplasia (ADH) which could not be excluded from the possibility of ductal carcinoma in situ (DCIS) was finally confirmed to be invasive breast cancer by open surgery (OS). One case of complex sclerosing lesions/radial scars (CSL/ RS) which was discordant with image finding was confirmed to be invasive breast cancer through OS. One case of papillary lesions/atypical ductal hyperplasia (PL/ADH) which had a higher risk of malignant potential was received OS subsequently and verified to be intraductal carcinoma with lobular carcinoma [26]. Besides, 5 cases were followed up after VAEB, and found recurrences at the sites of

Table 1 The distributions of benign, B3 or malignant breast lesions according to BI-RADS-US

\begin{tabular}{|c|c|c|c|c|c|c|c|}
\hline BI-RADS category & Total & Benign & Rate (\%) & B3 & Rate (\%) & Malignant & Rate $(\%$ \\
\hline 0 & 5 & 3 & 60 & 2 & 40 & 0 & 0 \\
\hline 2 & 141 & 138 & 97.9 & 3 & 2.1 & 0 & 0 \\
\hline 3 & 1735 & 1568 & 90.4 & 134 & 7.7 & 33 & 1.9 \\
\hline $4 a$ & 291 & 235 & 80.8 & 32 & 11.0 & 24 & 8.2 \\
\hline $4 b$ & 44 & 28 & 63.6 & 4 & 9.1 & 12 & 27.3 \\
\hline $4 c$ & 21 & 14 & 66.7 & 0 & 0 & 7 & 33.3 \\
\hline 5 & 8 & 0 & 0 & 0 & 0 & 8 & 100 \\
\hline
\end{tabular}

BI-RADS the Breast Imaging Reporting and Data System, US ultrasound 
Table 2 Malignancy underestimation rates of B3 subtypes

\begin{tabular}{llll}
\hline B3 subtype & Number & Underestimation & Rate (\%) \\
\hline ADH & 13 & 3 & 23.1 \\
FEA & 4 & 0 & 0 \\
LN & 3 & 0 & 0 \\
PL & 84 & 2 & 2.4 \\
PL/ADH & 2 & 1 & 50 \\
PT & 71 & 1 & 1.4 \\
CSL/RS & 6 & 1 & 16.7 \\
\hline
\end{tabular}

$\overline{A D H}$ atypical ductal hyperplasia, $F E A$ flat epithelial atypia, $L N$ classical lobular neoplasia, $P L$ papillary lesions, $P L / A D H$ papillary lesions/atypical ductal hyperplasia, PT phyllodes tumors, CSL/RS complex sclerosing lesions/radial scars

operation, which were demonstrated as malignancies via OS, including 2 cases of $\mathrm{ADH}$ confirmed to be DCIS and invasive ductal carcinoma respectively, 2 cases of PL confirmed to be DCIS and invasive ductal carcinoma, 1 case of phyllodes tumors (PT) diagnosed as invasive breast cancer. In general, the cumulative risk of malignancy underestimation in the B3 cohort was $4.4 \%$ (8/183). The individual malignancy underestimation rates of B3 subtypes were displayed in Table 2 . It is noteworthy that the most often underrated B3 subtypes were PL/ADH 50\% (1/2), ADH 23.1\% (3/13), and CSL/RS 16.7\% (1/ $6)$. The results are in line with the reports $[26,27]$. Although the malignancy underestimation rate of $\mathrm{B} 3$ is limited, multidisciplinary communication and imaging follow-up are necessary so as not to miss malignant potential [28].

After the period of follow-up, the recurrence rates of B3 subtypes were summarized in Table 3. We noticed that the highly frequent recurrences of $\mathrm{B} 3$ subtypes were ADH 10\% (1/10), PT 8.6\% (6/70), and PL 4.9\% (4/82). The recurrence rates of the later two subtypes are concordant with the literature $[29,30]$. Whether the higher recurrence rate of $\mathrm{ADH}$ was due to its fewer cases needs further observation.

Table 3 Recurrence rates of B3 subtypes

\begin{tabular}{llll}
\hline B3 subtype & Number & Recurrence & Rate (\%) \\
\hline ADH & 10 & 1 & 10 \\
FEA & 4 & 0 & 0 \\
LN & 3 & 0 & 0 \\
PL & 82 & 4 & 4.9 \\
PL/ADH & 1 & 0 & 0 \\
PT & 70 & 6 & 8.6 \\
CSL/RS & 5 & 0 & 0
\end{tabular}

$A D H$ atypical ductal hyperplasia, $F E A$ flat epithelial atypia, $L N$ classical lobular neoplasia, $P L$ papillary lesions, $P L / A D H$ papillary lesions/atypical ductal hyperplasia, $P T$ phyllodes tumors, CSL/RS complex sclerosing lesions/radial scars
The specific ultrasonic features and patients' characters of B3 comparing to those of benign or malignant cases

In clinical practice, uncertain malignant potentials are the most frequent causes which disturb both patients and physicians. To a certain extent, this could explain why most of the biopsy cases are nonmalignant breast disorders. One question is presented here that could we get any clues for B3 changes before the excision biopsy? Therefore, we analyzed the differences between the ultrasonic features corresponding to B3 lesions before VAEB and their associated patients' characteristics and those of benign or malignant cases by Chi-square test / Fisher's exact test. Negative statistic analyses included the complaint of pain, palpable nodules, lesions in left or right, quadrant of lesions, echo pattern, multifocality, duct changes and lymph nodes. To our best knowledge, it's the first time that we noticed that among B3 cases, the incidences of non-menopausal patients $(P=0.002)$, single $(P=0.000)$ or vascularity nodules $(P=0.000)$ in ultrasound findings were significantly increased, compared to those of benign cases. Also, the incidence of the irregular shape of nodules in $\mathrm{B} 3$ cases tended to be higher than that of benign cases $(P=0.080)$ (Table 4$)$. In the meantime, we compared malignant cases with $\mathrm{B} 3$ cases and found that the incidences of patients elder than 50 years $(P=0.000)$, nonreproductive age $(P=0.000)$ and menopause $(P=0.000)$, and lesions with irregular shape $(P=0.000)$, uncircumscribed margin $(P=0.000)$, vascularity $(P=0.002)$ or suspicious calcification $(P=0.000)$ in ultrasound findings were significantly increased in malignant cases (Table 4). Furthermore, both univariate and multivariate binary logistic regression analyses (B3 vs benign) showed that non-menopausal patients, single or vascularity nodules were significant risk factors for B3 occurrences (Table 5). While malignant compared to B3, univariate binary logistic regression analyses showed that patients elder than 50 years, and unclear margin, vascularity or suspicious calcification lesions were closely associated with malignancies. Moreover, multivariate logistic regression analyses demonstrated that patients elder than 50 years, unclear margin or suspicious calcification lesions were significant risk factors of malignant potential for B3 cases (Table 6). On these grounds, we reviewed the 8 malignancy underestimation cases in the B3 cohort and found that they presented with at least one or more malignant risk factors.

\section{Discussion}

B3 lesions are borderline with either benign or malignant breast disorders. Women with these lesions are often suffering from psychological depression because of an increased risk of finding concomitant cancer, or evolution toward in situ or invasive cancer over a long time $[26,30]$. The patients that underwent a breast biopsy claimed that they also have experienced biopsy-related stress even if the results were nonmalignant [31]. 
Table 4 Comparison between characteristics of B3 cases and those of benign or malignant cases

\begin{tabular}{|c|c|c|c|c|c|c|c|c|}
\hline & Benign & B3 & $x^{2}$ & $P$ & B3 & Malignant & $x^{2}$ & $P$ \\
\hline \multicolumn{9}{|l|}{ Age } \\
\hline$\leq 50$ & 1809 & 165 & 2.081 & 0.149 & 165 & 56 & 34.583 & 0.000 \\
\hline$>50$ & 177 & 10 & & & 10 & 28 & & \\
\hline \multicolumn{9}{|l|}{ Pain } \\
\hline No & 1913 & 164 & 2.93 & 0.087 & 164 & 76 & 0.88 & 0.35 \\
\hline Yes & 73 & 11 & & & 11 & 8 & & \\
\hline \multicolumn{9}{|c|}{ Duct changes } \\
\hline No & 1912 & 168 & 0.033 & 0.86 & 168 & 80 & 0.081 & 0.78 \\
\hline Yes & 74 & 7 & & & 7 & 4 & & \\
\hline \multicolumn{9}{|c|}{ Lymph nodes } \\
\hline No & 1950 & 170 & 0.943 & 0.33 & 170 & 81 & 0.097 & 0.76 \\
\hline Yes & 36 & 5 & & & 5 & 3 & & \\
\hline \multicolumn{9}{|c|}{ Palpable } \\
\hline Yes & 1727 & 151 & 0.06 & 0.8 & 151 & 70 & 0.40 & 0.53 \\
\hline No & 259 & 24 & & & 24 & 14 & & \\
\hline
\end{tabular}

Left/right

$$
\text { Left }
$$

Right

Quadrant

Areola
Upper outer
Upper inner
Lower inner
Lower outer

Echo pattern

Anechoic
Hyperechoic
Complex cystic/solid
Hypoechoic
Heterogeneous

\section{Reproductive age}

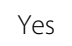

No

\section{Menopause}

No
Yes

Multifocality

$$
\begin{aligned}
& \text { Unifocal } \\
& \text { Multifocal }
\end{aligned}
$$

\section{Shape}

$$
\begin{aligned}
& \text { Regular } \\
& \text { Irregular }
\end{aligned}
$$

Margin

Circumscribed 
Table 4 Comparison between characteristics of B3 cases and those of benign or malignant cases (Continued)

\begin{tabular}{|c|c|c|c|c|c|c|c|c|}
\hline & Benign & B3 & $x^{2}$ & $P$ & B3 & Malignant & $x^{2}$ & $P$ \\
\hline Not circumscribed & 375 & 30 & & & 30 & 55 & & \\
\hline \multicolumn{9}{|c|}{ Suspicious calcification } \\
\hline Absent & 1864 & 168 & 1.316 & 0.572 & 168 & 56 & 41.785 & 0.000 \\
\hline Present & 122 & 7 & & & 7 & 28 & & \\
\hline \multicolumn{9}{|l|}{ Vascularity } \\
\hline Absent/scarce & 1847 & 142 & 30.870 & 0.000 & 142 & 53 & 9.937 & 0.002 \\
\hline Present & 139 & 33 & & & 33 & 31 & & \\
\hline
\end{tabular}

While concern about over-diagnosis and overtreatment through breast screening is on the increase, it must be considered the strategies to manage breast abnormalities because the approaches differences are not trivial and could translate into possibly thousands of patients undergoing unnecessary biopsies or an equal number with delays in diagnoses of malignancies [28].

Our data showed that the overwhelming majority of histopathological results of the 2245 US-VAEB cases were benign breast disorders (88.5\%), and only a small proportion (3.4\%) was malignancies. The results are consistent with the literature $[11,18-20]$. It shows that criteria should be more strict to avoid unnecessary VAEB procedures for the patient's clinical and economic benefit unless there is a specific request from the patient. Our data showed that $8.2 \%$ of the 2245 VAEB cases were proved to be B3 lesions. The overall malignancy underestimation rate for this clinical dilemma was $4.4 \%$. The data suggested that excision biopsies are not needed for most of these borderline changes as well. Furthermore, we noticed that B3 high frequently occurred in the range of BI-RADS-US 3-4b, which is partly

Table 5 Binary logistic regression analyses between characteristics of benign cases and those of B3 cases

\begin{tabular}{|c|c|c|c|c|}
\hline & \multicolumn{2}{|l|}{ Univariate } & \multicolumn{2}{|l|}{ Multivariate } \\
\hline & OR $(95 \% \mathrm{Cl})$ & $P$ & OR $(95 \% \mathrm{Cl})$ & $P$ \\
\hline \multicolumn{5}{|l|}{ Menopause } \\
\hline Yes & $3.491(1.528,7.976)$ & 0.003 & $3.745(1.628,8.616)$ & 0.002 \\
\hline \multicolumn{5}{|l|}{ No } \\
\hline \multicolumn{5}{|l|}{ Multifocality } \\
\hline Multifocal & $1.994(1.442,2.757)$ & 0.000 & $1.905(1.370,2.650)$ & 0.000 \\
\hline \multicolumn{5}{|l|}{ Unifocal } \\
\hline \multicolumn{5}{|l|}{ Shape } \\
\hline Regular & $1.488(0.951,2.329)$ & 0.082 & $1.259(0.788,2.014)$ & 0.336 \\
\hline \multicolumn{5}{|l|}{ Irregular } \\
\hline \multicolumn{5}{|l|}{ Vascularity } \\
\hline Absent/scarce & $3.088(2.037,4.682)$ & 0.000 & $2.691(1.745,4.150)$ & 0.000 \\
\hline Present & & & & \\
\hline
\end{tabular}

consistent with the reports [31, 32]. And the data showed that the most often underrated B3 subtypes were PL/ADH (50\%), $\mathrm{ADH}$ (23.1\%), and CSL/RS (16.7\%), respectively. Moreover, the most frequent recurrence rates of B3 subtypes were $\mathrm{ADH}(10 \%), \mathrm{PT}$ (8.6\%), and PL (4.9\%). These are compatible with the previous study [33]. In a word, taking into account both the incidence and the overall malignancy underestimation rate of $\mathrm{B} 3$ lesions, only a minority of B3 cases should be subjected to VAEB. If consideration on B3 subtypes' malignancy underestimation rates and their recurrence rates, we recommend re-biopsy/OS for $\mathrm{PL} /$ $\mathrm{ADH}, \mathrm{ADH}$, and $\mathrm{PT}$ subtypes, which is in accordance with the reports [29, 34, 35].

At present, several studies refer to ultrasonic features before VAEB corresponding to B3 lesions and their associated patients' characteristics but they all are either lack statistical analyses or categorizing B3 into normal lesions for analyses $[15,23,36]$. Therefore, the data could hardly help to identify B3 from benign or malignant breast changes. For the first time, we found that the incidences of non-menopausal patients, single or vascularity nodules were significantly increased in B3 cases compared to those of benign cases. Besides these, the incidence of nodules with irregular shape in B3 cases tended to be higher than that of normal cases $(P=0.080)$. Then, multivariate logistic regression analyses demonstrated that non-menopausal women, single or vascularity nodules were significant risk factors for B3 cases. Combining with the above mentioned, it indicated that breast lesions in the range of BI-RADS-US grade 3-4b presenting with one or more of the above risk factors before VAEB should be aware of B3 occurrences. On the other hand, compared to B3 cases, the incidences of patients elder than 50 years, non-reproductive age and menopause, and irregular shape, uncircumscribed margin, vascularity or suspicious calcification lesions were significantly increased in malignant cases. Furthermore, multivariate logistic regression analyses showed that patients elder than 50 years, unclear margin or suspicious calcification lesions were significant risk factors of malignant potential for B3 cases. It suggested that the B3 cases confirmed post-US-VAEB, which were classified into BI-RADS-US 
Table 6 Binary logistic regression analyses between characteristics of malignant cases and those of B3 cases

\begin{tabular}{|c|c|c|c|c|}
\hline & \multicolumn{2}{|l|}{ Univariate } & \multicolumn{2}{|l|}{ Multivariate } \\
\hline & OR $(95 \% \mathrm{Cl})$ & $P$ & OR $(95 \% \mathrm{Cl})$ & $P$ \\
\hline \multicolumn{5}{|l|}{ Age } \\
\hline$\leq 50$ & $8.25(3.770,18.053)$ & 0.000 & $7.936(3.178,19.816)$ & 0.000 \\
\hline \multicolumn{5}{|l|}{$>50$} \\
\hline \multicolumn{5}{|l|}{ Margin } \\
\hline Circumscribed & $9.167(5.044,16.659)$ & 0.000 & $7.101(3.571,14.119)$ & 0.000 \\
\hline \multicolumn{5}{|c|}{ Not circumscribed } \\
\hline \multicolumn{5}{|l|}{ Microcalcification } \\
\hline Absent & $12.000(4.969,28.981)$ & 0.000 & $11.101(4.010,30.733)$ & 0.000 \\
\hline \multicolumn{5}{|l|}{ Present } \\
\hline \multicolumn{5}{|l|}{ Vascularity } \\
\hline Absent/scarce & $2.517(1.405,4.509)$ & 0.001 & $1.711(0.808,3.623)$ & 0.161 \\
\hline Present & & & & \\
\hline
\end{tabular}

grade $4 b-5$ as we discussed earlier, with one or more of the above malignant risk factors should be watched out for malignancy underestimation.

\section{Study limitations}

The first is the fewer cases of the B3 cohort and the retrospective nature of the study. The second limitation is that there is a lack of ultrasonic features of B3 subtypes and their associated patients' characteristics which allow more accurate comparisons between B3 and benign or malignant cases. Finally, this study did not analyze the influence of the family history of breast cancer on first-degree relatives, and the influence of age as a continuous variable in point of malignancy risk factors $[37,38]$. Hence, further studies are required in these regards.

\section{Conclusions}

The vast majority of cases conducted US-VAEB were proved to be benign breast changes. The cases assigned in the range of BI-RADS-US grade $3-4 b$ with one or more factors of non-menopausal patients, single or vascularity nodules should be cautious of B3 occurrences. For these cases, close clinical and imaging follow-up is recommended. The B3 cases confirmed post-US-VAEB, which were classified into BI-RADS-US grade $4 \mathrm{~b}-5$, with one or more factors of elder than 50 years, unclear margin or suspicious calcification lesions were remarkably related to malignant potential. For these cases, interval re-biopsy/OS should be considered subsequently postUS-VAEB to avoid malignancy underestimation. If confirmed on larger series and prospectively validated, the results could help to improve strategies to identify B3 from benign breast abnormalities before VAEB and reduce the malignancy underestimation of B3.

\section{Abbreviations}

B3: Uncertain malignant potential; VAEB: Vacuum-assisted excision biopsy; US: Ultrasound; DCIS: Ductal carcinoma in situ; ADH: Atypical ductal hyperplasia; FEA: Flat epithelial atypia; LN: Classical lobular neoplasia; PL: Papillary lesions; PL/ADH: Papillary lesions/atypical ductal hyperplasia; PT: Phyllodes tumors; CSL/RS: Complex sclerosing lesions/radial scars; 95\% Cl: 95\% confidence interval; OR: Odds ratio

\section{Acknowledgements}

Not applicable.

\section{Authors' contributions}

Wenjian Wang conceived the original idea, supervised the project, and wrote the draft. Liang Zheng, Fufu Zheng, and Zhaomin Xing collected the data, performed the statistical analysis, and wrote the results. Yuanhui Lai, Jie Li, Yunjian Zhang, Yongxin Li and Hongbiao Xu performed VAEB and collected the data. All authors discussed the results and contributed to the final article.

The authors read and approved the final manuscript.

\section{Funding}

This study was supported by the National Natural Science Foundation of China (Grant No. 81872130) and the China National Natural Science Foundation of Guangdong (Grant No. 2017A030311001).

Availability of data and materials

All data generated or analyzed during this study are included in this published article.

\section{Declarations}

\section{Ethics approval and consent to participate}

The study was approved by the Institute Research Ethics Committee of the First Affiliated Hospital of Sun Yat-sen University granted permission for this retrospective study. The informed consent was obtained from all participants or from a parent and/or legal guardian. All procedures performed in this study were in accordance with relevant national and/or international guidelines and regulations.

Consent for publication

Not applicable.

Competing interests

The authors declare that there are no potential conflicts of interest disclosed. 


\section{Author details}

'Laboratory of Department of Surgery, the First Affiliated Hospital of Sun Yat-sen University, Guangzhou 510080, Guangdong, China. ${ }^{2}$ Department of Thyroid and Breast Surgery, the First Affiliated Hospital of Sun Yat-sen University, Guangzhou 510080, Guangdong, China. ${ }^{3}$ Department of Urology, the First Affiliated Hospital of Sun Yat-sen University, Guangzhou 510080, Guangdong, China. ${ }^{4}$ Department of Vascular Surgery, the Affiliated Hospital of Qingdao University, Qingdao 266000, Shandong, China.

\section{Received: 12 March 2021 Accepted: 18 May 2021}

\section{Published online: 29 May 2021}

\section{References}

1. Ferlay J, Colombet M, Soerjomataram I, Mathers C, Parkin DM, Piñeros M, et al. Estimating the global cancer incidence and mortality in 2018: GLOBOCAN sources and methods. Int J Cancer. 2019;144(8):1941-53. https://doi.org/10.1002/ijc.31937.

2. Feng RM, Zong YN, Cao SM, Xu RH. Current cancer situation in China: good or bad news from the 2018 global Cancer statistics? Cancer Commun (Lond). 2019;39(1):22. https://doi.org/10.1186/s40880-019-0368-6.

3. Stachs A, Stubert J, Reimer T, Hartmann S. Benign breast disease in women. Dtsch Arztebl Int. 2019;116(33-34):565-74. https://doi.org/10.3238/arztebl.2 019.0565 .

4. Raza S, Goldkamp AL, Chikarmane SA, Birdwell RL. US of breast masses categorized as BI-RADS 3, 4, and 5: pictorial review of factors influencing clinical management. Radiographics. 2010;30(5):1199-213. https://doi.org/1 0.1148/rg.305095144

5. Shang J, Ruan LT, Wang YY, Zhang XJ, Dang Y, Liu B, et al. Utilizing sizebased thresholds of stiffness gradient to reclassify BI-RADS category 3-4b lesions increases diagnostic performance. Clin Radiol. 2019;74(4):306-13. https://doi.org/10.1016/j.crad.2019.01.004.

6. Chae EY, Cha JH, Shin HJ, Choi WJ, Kim HH. Reassessment and follow-up results of BI-RADS category 3 lesions detected on screening breast ultrasound. AJR Am J Roentgenol. 2016;206(3):666-72. https://doi.org/1 0.2214/AJR.15.14785.

7. Zhang Z, Zhang X, Lin X, Dong L, Zhang S, Zhang X, et al. Ultrasonic diagnosis of breast nodules using modified faster R-CNN. Ultrason Imaging. 2019;41(6):353-67. https://doi.org/10.1177/0161734619882683.

8. Chen M, Zhan WW, Wang WP. Cystic breast lesions by conventional ultrasonography: sonographic subtype-pathologic correlation and BI-RADS assessment. Arch Med Sci. 2014;10(1):76-83. https://doi.org/10.5114/aoms.2 014.40734 .

9. Tamaki K, Sasano H, Ishida T, Ishida K, Miyashita M, Takeda M, et al. The correlation between ultrasonographic findings and pathologic features in breast disorders. Jpn J Clin Oncol. 2010;40(10):905-12. https://doi.org/10.1 093/jjco/hyq070

10. Spak DA, Plaxco JS, Santiago L, Dryden MJ, Dogan BE. BI-RADS((R)) fifth edition: a summary of changes. Diagn Interv Imaging. 2017;98(3):179-90. https://doi.org/10.1016/j.diii.2017.01.001.

11. Luo HJ, Chen X, Tu G, Wang J, Wu CY, Yang GL. Therapeutic application of ultrasound-guided 8-gauge Mammotome system in presumed benign breast lesions. Breast J. 2011;17(5):490-7. https://doi.org/10.1111/j.1524-4 741.2011.01125.x.

12. Bozzini A, Cassano E, Raciti D, Disalvatore D, Pala O, Vingiani A, et al. Analysis of efficacy and accuracy of 2 vacuum-assisted breast biopsy devices: Mammotome and elite. Clin Breast Cancer. 2018;18(6):e1277-82. https://doi.org/10.1016/j.clbc.2018.06.014.

13. Park HL, Kim KY, Park JS, Shin JE, Kim HR, Yang B, et al. Clinicopathological analysis of ultrasound-guided vacuum-assisted breast biopsy for the diagnosis and treatment of breast disease. Anticancer Res. 2018;38(4):245562. https://doi.org/10.21873/anticanres.12499.

14. Bennett I, de Viana D, Law M, Saboo A. Surgeon-performed vacuum-assisted biopsy of the breast: results from a multicentre Australian study. World J Surg. 2020;44(3):819-24. https://doi.org/10.1007/s00268-019-05266-7.

15. Perretta $T$, Lamacchia F, Ferrari $D$, et al. Evaluation of ultrasound-guided 8gauge vacuum-assisted excision system for the removal of US-detectable breast lesions. Anticancer Res. 2020;40(3):1719-29. https://doi.org/10.21873/a nticanres.14125.

16. Orsaria P, Grasso A, Carino R, Caredda E, Sammarra M, Altomare C, et al. Heterogeneous risk profiles among B3 breast lesions of uncertain malignant potential. Tumori. 2020;106(2):115-25. https://doi.org/10.1177/030089161 9868301.

17. Pinder SE, Shaaban A, Deb R, Desai A, Gandhi A, Lee AHS, et al. NHS breast screening multidisciplinary working group guidelines for the diagnosis and management of breast lesions of uncertain malignant potential on core biopsy (B3 lesions). Clin Radiol. 2018;73(8):682-92. https://doi.org/10.1016/j. crad.2018.04.004.

18. Jiang $\mathrm{Y}$, Lan $\mathrm{H}$, Ye $\mathrm{Q}$, et al. Mammotome((R)) biopsy system for the resection of breast lesions: clinical experience in two high-volume teaching hospitals. Exp Ther Med. 2013;6(3):759-64. https://doi.org/10.3892/etm.2013.1191.

19. Thomas PS. Diagnosis and Management of High-Risk Breast Lesions. J Natl Compr Cancer Netw. 2018;16(11):1391-6. https://doi.org/10.6004/jnccn.2018. 7099 .

20. Olarinoye-Akorede SA, Yunusa GH, Aliyu H, Hamidu AU. Breast imaging reporting and data systems category 3 (probably benign) breast lesions detected on diagnostic breast ultrasound: the prevalence, outcome and malignancy detection rate in Zaria, Nigeria. SA J Radiol. 2018;22(2):1315. https://doi.org/10.4102/sajr.v22i2.1315.

21. Li L, Wu J, Pu D, Zhao Y, Wan C, Sun L, et al. Factors associated with the age of natural menopause and menopausal symptoms in Chinese women. Maturitas. 2012;73(4):354-60. https://doi.org/10.1016/.jmaturitas.2012.09.008.

22. Rao AA, Feneis J, Lalonde C, Ojeda-Fournier H. A pictorial review of changes in the BI-RADS fifth edition. Radiographics. 2016;36(3):623-39. https://doi. org/10.1148/rg.2016150178.

23. Giuliani M, Rinaldi P, Rella R, D'Angelo A, Carlino G, Infante A, et al. A new risk stratification score for the management of ultrasound-detected $B 3$ breast lesions. Breast J. 2018;24(6):965-70. https://doi.org/10.1111/tbj.13115.

24. Elsharkawy M, Vestring $T$, Raatschen $\mathrm{HJ}$. A ten-year, single-center experience: concordance between breast core needle biopsy/vacuum-assisted biopsy and postoperative histopathology in B3 and B5a cases. PLoS One. 2020; 15(5):e0233574. https://doi.org/10.1371/journal.pone.0233574.

25. Houssami N, Ciatto $S$, Ellis I, Ambrogetti D. Underestimation of malignancy of breast core-needle biopsy: concepts and precise overall and categoryspecific estimates. Cancer. 2007;109(3):487-95. https://doi.org/10.1002/ cncr.22435.

26. Ugurlu MU, Yoldemir T, Gulluoglu BM. Assessment and management of B3 breast lesions with atypia: a focused review. Climacteric. 2020;23(1):17-23. https://doi.org/10.1080/13697137.2019.1660637.

27. Grippo C, Jagmohan P, Clauser P, et al. External Validation of a Risk Stratification Score for B3 Breast Lesions Detected at Ultrasound Core Needle Biopsy. Diagnostics (Basel). 2020;10(4).

28. Georgian-Smith D, Lawton TJ. Variations in physician recommendations for surgery after diagnosis of a high-risk lesion on breast core needle biopsy. AJR Am J Roentgenol. 2012;198(2):256-63. https:/doi.org/10.2214/AJR.11.7717.

29. Bekes I, deGregorio A, deWaal A, et al. Review on current treatment options for lesions of uncertain malignant potential (B3 lesions) of the breast: do B3 papillary lesions need to be removed in any case by open surgery? Arch Gynecol Obstet. 2019;300(2):481-4. https://doi.org/10.1007/s00404-018-4985-0.

30. Renshaw AA, Gould EW. Long term clinical follow-up of atypical ductal hyperplasia and lobular carcinoma in situ in breast core needle biopsies. Pathology. 2016;48(1):25-9. https://doi.org/10.1016/j.pathol.2015.11.015.

31. Pistolese CA, Lamacchia F, Tosti D, et al. Reducing the number of unnecessary percutaneous biopsies: the role of second opinion by expert breast center radiologists. Anticancer Res. 2020;40(2):939-50. https://doi. org/10.21873/anticanres.14027.

32. Hodorowicz-Zaniewska D, Siarkiewicz B, Brzuszkiewicz K, Szpor J. Underestimation of breast cancer in intraductal papillomas treated with vacuum-assisted core needle biopsy. Ginekol Pol. 2019;90(3):122-7. https:// doi.org/10.5603/GP.2019.0022.

33. Londero V, Zuiani C, Linda A, Battigelli L, Brondani G, Bazzocchi M. Borderline breast lesions: comparison of malignancy underestimation rates with 14-gauge core needle biopsy versus 11-gauge vacuum-assisted device. Eur Radiol. 2011;21 (6):1200-6. https://doi.org/10.1007/s00330-010-2053-7.

34. Bianchi S, Bendinelli B, Saladino V, Vezzosi V, Brancato B, Nori J, et al. Nonmalignant breast papillary lesions - b3 diagnosed on ultrasound--guided 14gauge needle core biopsy: analysis of 114 cases from a single institution and review of the literature. Pathol Oncol Res. 2015;21(3):535-46. https://doi. org/10.1007/s12253-014-9882-7.

35. Hodorowicz-Zaniewska D, Szpor J, Basta P. Intraductal papilloma of the breast - management. Ginekol Pol. 2019;90(2):100-3. https://doi.org/10.5603/ GP.2019.0017. 
36. Forester ND, Lowes S, Mitchell E, Twiddy M. High risk (B3) breast lesions: what is the incidence of malignancy for individual lesion subtypes? A systematic review and meta-analysis. Eur J Surg Oncol. 2019;45(4):519-27. https://doi.org/10.1016/j.ejso.2018.12.008.

37. Paulinelli RR, Freitas-Junior $R$, de Lucena $C E$, et al. Sonobreast: predicting individualized probabilities of malignancy in solid breast masses with echographic expression. Breast J. 2011;17(2):152-9. https://doi.org/10.1111/ j.1524-4741.2010.01046.x.

38. Paulinelli RR, Oliveira LF, Freitas-Junior R, et al. The accuracy of the SONOBREAST statistical model in comparison to BI-RADS for the prediction of malignancy in solid breast nodules detected at ultrasonography. Eur J Obstet Gynecol Reprod Biol. 2016;196:1-5. https://doi.org/10.1016/j.jogrb.2 015.09.031.

\section{Publisher's Note}

Springer Nature remains neutral with regard to jurisdictional claims in published maps and institutional affiliations.

\section{Ready to submit your research? Choose BMC and benefit from:}

- fast, convenient online submission

- thorough peer review by experienced researchers in your field

- rapid publication on acceptance

- support for research data, including large and complex data types

- gold Open Access which fosters wider collaboration and increased citations

- maximum visibility for your research: over $100 \mathrm{M}$ website views per year

At $\mathrm{BMC}$, research is always in progress.

Learn more biomedcentral.com/submissions 